\title{
Dinâmicas migratórias e internacionalização do ensino superior
}

Fernando Lajus ${ }^{1}$

\section{RESUMO}

O artigo debate os fluxos migratórios contemporâneos e a sua relação com a internacionalização do Ensino Superior, colocando em cena o caso dos estudantes congoleses na Universidade Federal do Paraná. Discutese, para tanto, o que se entende por internacionalização e seu papel na elaboração de políticas para a Educação Universitária; os programas que fazem parte desse processo no contexto brasileiro e, mais especificamente, na UFPR, como o PEC-G e o PROVAR; se apresentam os resultados de pesquisa qualitativa realizada junto aos estudantes congoleses e as considerações sobre os impactos que este processo tem tanto para a universidade quanto para as dinâmicas migratórias mais amplas, materializadas nos casos de refugiados e apátridas, por exemplo. Percebe-se que a internacionalização do Ensino Superior perpassa as estratégias migratórias daqueles em processo de deslocamento espacial, ainda que de forma desigual dentro de um cenário internacional desigual.

Palavras-chave: Migração; Migração estudantil; Internacionalização; PEC-G

\begin{abstract}
The article discusses the contemporary migration flux and its relation to the internationalization of the Higher Education system, putting into the scene the case of Congolese students in the Federal University of Paraná. For that purpose, the article elaborates on the understating of the term internationalization and its role on the elaboration of policies

${ }^{1}$ Mestrando do Programa de Pós Graduação de Sociologia da Universidade Federal do Paraná, na área de Sociologia da Migração, orientado pelo Professor Márcio de Oliveira. Estuda migrações contemporâneas, em especial naquilo que concerne ao caso da internacionalização do Ensino Superior. Trabalha também como voluntário na ONG Cáritas Paraná, no setor de auxílio jurídico. Email: flajuso7@gmail.com.
\end{abstract}


for the Higher Education System; the programs that are active in Brazil and, more specifically, in the Federal University of Paraná, such as PEC$G$ and PROVAR; presents the qualitative results of a research made with the Congolese students and the impact that this process has for both the university and to other migratory dynamics, such is the case for refugees and stateless persons, for example. It is acknowledged that the internationalization of the Higher Education System overarch the migratory strategies of those in geographical displacement, even though this happens in an unequal context of educational fluxes.

Key-words: Migration; Educational migration; Internationalization; PEC-G.

O artigo apresentado parte dos questionamentos levantados em pesquisa monográfica apresentada no ano de 2017 como requisito para a obtenção do diploma de bacharel em Ciências Sociais pela Universidade Federal do Paraná (doravante UFPR) (Lajus, 2017). A maior parte das considerações que se seguem, bem como os dados apresentados, são frutos deste projeto de pesquisa. O material complementar, exposto sobretudo no último trecho do artigo, é decorrente de um esforço posterior de pesquisa, e trata de um questionamento que hoje me parece central, mas que ainda não havia sido formulado no trabalho monográfico.

O interesse da pesquisa esteve centrado nas práticas dos estudantes internacionais no Ensino Superior brasileiro, atentando para a trajetória de um grupo específico no interior da UFPR e as maneiras como estes davam sentido a sua trajetória internacional. Mas, antes de qualquer aproximação a este problema específico, é preciso atentar para o contexto de discussão no qual as políticas de internacionalização da Educação Superior estão sendo discutidas.

Neste caso, vê-se que, no âmbito dos órgãos internacionais de debate o surgimento da internacionalização já está presente ao menos 
desde a Conferência Mundial sobre a Educação Superior, realizada em 1998 em Paris pela UNESCO (UNESCO, 1998). ${ }^{2}$ Tal debate sobre este eixo específico das políticas no Ensino Superior será formalizado em 2009, em congresso com o mesmo nome (UNESCO, 2009). Não que anterior a década de 1990 práticas para internacionalizar o currículo não existissem. O que passa ocorrer, juntamente com o advento de novos meios de comunicação, é uma crescente preocupação institucional com os fluxos internacionais de conhecimentos, que tem como um de seus vetores o deslocamento espacial de estudantes.

Para se compreender os significados dos processos de internacionalização do Ensino Superior, Jane Knight (2015) nos dá uma boa definição:

Internationalization at the national, sector, and institutional levels is defined as the process of integrating an international, intercultural, or global dimension into the purpose, functions or delivery of postsecondary education (KNIGHT, Jane, 2015, p.3). ${ }^{3}$

Dois pontos de interesse podem ser retirados desta definição. Primeiro, há um aumento dos espaços onde o processo de internacionalização pode ocorrer. Aqui se trata de localizar em qual âmbito ela ocorre, seja nacional, regional ou ainda em nível institucional. Tal abordagem nos permite olhar para os diferentes atores em ação no processo de definição e manutenção das políticas para internacionalizar o ensino. O segundo aspecto de interesse é que a

\footnotetext{
${ }^{2}$ Os artigos 15ํㅜ e 16ำ são aqueles que falam mais diretamente sobre as práticas para desenvolver um sistema de ensino superior internacional e os desafios desse processo. In: http://www.direitoshumanos.usp.br/index.php/Direito-aEduca\% $\mathrm{C}_{3} \% \mathrm{~A}_{7} \% \mathrm{C}_{3} \% \mathrm{~A}_{3}$ /declaracao-mundial-sobre-educacao-superior-no-seculo-xxivisao-e-acao.html. Acesso em 08/02/2019.

3 "Seja no nível nacional, regional ou institucional, a internacionalização é definida como o processo de integrar uma dimensão internacional, intercultural ou global aos propósitos, funções ou atividades da educação pós-secundário".
} 
definição engloba uma série de práticas da Educação Superior. Ela permite tanto olhar para o envio e o recebimento de alunos quanto para a elaboração de currículos, treinamento de pessoal técnico e professoral e formação de acordos bi e multi-laterais.

Uma questão, entretanto, se mantém em aberto, qual seja, a de se saber então qual seriam os motivos de elaboração de políticas para a internacionalização do Educação Superior? Seja no nível nacional ou no institucional, o que justifica a alocação de recursos num ensino internacional? De Wit (200o) discute o que chame de "rationales", empregados nessas justificativas. Uma dessas justificativas é de ordem política. De Wit (200o, p.13) traça o surgimento dessa tendência ao período posterior a segunda guerra mundial, e ao confronto, durante a guerra fria, entre as duas potências mundiais, E.U.A e União Soviética. Um dos objetivos seria aquele de exercer influência sobre outros países, na criação e manutenção de uma classe intelectual e técnica. A comissão Fulbright ${ }^{4}$ - até os dias de hoje uma das principais concedentes de bolsas para estudos nos E.U.A - surge em meio a este período. A lógica política emprega no seu funcionamento uma certa noção de civilidade adquirida durante o processo de deslocamento estudantil.

A segunda lógica é de aspecto econômico. Essa é a mais utilizada atualmente, e privilegia o foco nas práticas de um novo mercado de trabalho, apresentado como mais dinâmico e internacional. Esse é o principal modelo de instituições privadas e de conglomerados como o Universitas $21,{ }^{5}$ onde a educação internacional é tratada como um

${ }^{4}$ A comissão Fulbright foi criada por empenho do então senador J. Willian Fulbright, no ano de 1946. Apesar do discurso de empatia e otimismo que o então senador dispensava as práticas de internacionalização do Ensino e de sua simpatia à criação da ONU, o mesmo era um defensor de leis de segregação racial em seu país. In. https://fulbright.org.br/comissao/ https://libraries.uark.edu/info/exhibitgallery.asp?ExhibitID=244.

\footnotetext{
${ }^{5}$ In: https://universitas21.com/.
} 
commodity. Não à toa muitos dos programas que oferecem um ensino com estadas ou aulas com sede em outros países são ligados a práticas de business. Essa escolha marca a percepção geral de que cada vez mais aqueles que pretendem se inserir no mercado de trabalho irão precisar compreender dinâmicas internacionais de um mundo globalizado.

Para o caso das políticas destinadas a alavancar a educação no seu aspecto internacional se pode localizar o Estado como ator principal e por excelência desses processos de internacionalização. Ele é tanto o ator interessado na formação internacional de seus pesquisadores quanto o financiador dessas atividades.

Se o fluxo de pesquisadores e estudantes sempre foi algo constante, pelo menos para aqueles em posição de destaque em suas respectivas áreas de atuação, ou para aqueles que podiam, independentemente do financiamento por parte do Estado ou outras instituições, arcar com suas próprias viagens, vemos que tal preocupação, no caso do Estado brasileiro, só irá se iniciar em meados do século XX. Para aqueles que desejavam fazer pesquisa internacional, tal empreitada dependia muito de sua capacidade de se fazer conhecido fora do país. Assim era possível que, através da participação em grupos de pesquisa e estudos de outras localidades, ${ }^{6}$ o pesquisador conseguisse fundos com agências internacionais para o financiamento de sua viagem, estadia e pesquisa (SCHWARTZMAN, 2001).

Esta dinâmica de financiamento acarretava, muitas vezes, numa desigualdade de demandas de pesquisa, já que a agenda da mesma era definida pelos interesses de outras nações e grupos com realidades divergentes da nacional. Para aquele que desejasse fazer pesquisa de ponta na sua área de conhecimento restava a opção de participar de laboratórios internacionais que já estavam engajados em alguma

${ }^{6}$ No caso dos profissionais brasileiros, esses grupos se localizavam com especial importância na França, por diversos motivos, entre eles a língua, que foi durante muito tempo a língua estrangeira ensinada nas escolas do país. 
pesquisa específica. Além disso, tal modelo dependia da existência de pessoas chaves que aglutinavam ao seu redor recursos e pessoal. ${ }^{7}$ Para Laus (2004), esse modelo vigorou à partir da década de 1930 até meados de 1950, quando são então criadas a CAPES e o CNPq (FERREIRA e MOREIRA, 2002). Os dois órgãos passaram a ficar responsáveis pela disponibilização da concessão de bolsas; pelo pagamento das mesmas; pela supervisão das atividades realizadas e pelo estabelecimento das diretrizes a serem seguidas na concessão das bolsas. Esse processo iniciado pelo CAPES e pelo $\mathrm{CNPq}$ em âmbito nacional pode ser considerado pioneiro no espaço da América Latina (NIELSEN et al, 2005). Em estudo de 2002 do Banco Mundial, o sistema de Ensino Superior no Brasil é aquele que, no contexto da América Latina, mais possui professores com título de doutor, ${ }^{8}$ uma decorrência dessas políticas de formação de pessoal.

No contexto da América Latina, o Brasil ocupa papel decisivo na formulação de planos para o desenvolvimento de diversos aspecto da região. O acordo do Mercado Comum do Sul (MERCOSUL), por exemplo, além de estabelecer uma zona livre de comércio entre os países signatários, também facilita o fluxo migratório com origem no Ensino Superior entre os países (LAUS e MOROSINI, 2005). Em decisão recente do Conselho Mercado Comum (CMC), estrangeiros provenientes de

${ }^{7}$ Por mais que possa parecer um pouco com uma descrição dos tempos atuais, existem algumas diferenças marcantes entre este modelo e o atual, a principal sendo a existência de agências reguladoras que regulamentam a distribuição e manutenção das bolsas, como a CAPES e o CNPq. É através dessas agências que critérios de produção começam a ser sistematicamente empregados na concessão de bolsas de pesquisa.

${ }^{8}$ In:http://siteresources.worldbank.org/EXTLACREGTOPEDUCATION/Resou rces/Higher_Ed_in_LAC_Intnal_Dimension.pdf . p. 49. 
países do bloco do MERCOSUL irão poder solicitar a revalidação de seus diplomas em universidades brasileiras com o fim de lecionar no país. ${ }^{9}$

Destes acordos regionais e institucionais de promoção da internacionalização, uma série de estudos têm sido realizados. O campo de produção sobre os casos concretos de estudantes estrangeiros se organiza em torno de dois eixos. O primeiro deles se questiona sobre os efeitos do deslocamento de estudantes brasileiros para o exterior (LOMBAS, 2011; GUIMARÃES, 2002; SCHWARTZMAN, 2001; SOBRINHO, 2005; MOROSINI, 2011, BRUM, 2009, 2010, 2011, 2014; FERREIRA E MOREIRA, 2002; BRITO, 2004). Temas como formação internacional de uma elite intelectual; a manipulação de uma identidade brasileira em contexto internacionais e os limites do processo de internacionalização são frequentes.

O segundo eixo de produções trata daqueles estudantes estrangeiros que se encontram no Brasil (KALY, 2001; SUBUHANA, 2009; MASSART, 2002; MUNGOI, 2012; PIRES, BERNER e FRANÇA, 2016). Os trabalhos citados são ligados, sobretudo, ao fluxo de estudantes do continente africano para o Brasil. Os temas focalizados nessas pesquisas são o lugar do Brasil num cenário global de migrações estudantis, principalmente em relação as dinâmicas Sul-Sul, ou aquilo que Azevedo (2015) e Baumgarten (2007) chamaram de geopolítica do conhecimento científico; o preconceito racial no Brasil e os planos de vida desses estudantes.

Sobre o racismo os autores destacam algumas das especificidades das especificidades encontradas pelos estudantes africanos negros no Brasil. Primeiramente se tratam de estrangeiros: negros estrangeiros. Para Massart (2002) o pertencimento à categoria administrativa de estrangeiro surge com certa ambivalência. Primeiro ela

\footnotetext{
${ }^{9}$ In:http://www.capes.gov.br/images/stories/download/diversos/Mercosul_N OVAS_REGRAS.pdf.
} 
define o lugar exterior ao qual o estudante pertence em relação à sociedade brasileira: ele é alguém que veio para cá, mas que não é daqui. A segunda consequência de ser estrangeiro - esta mais próxima da discussão racial - é a forma como tal categoria impacta nas representações que se constroem sobre os estudantes do continente africano. Ser estrangeiro também é uma forma de diferenciação social em relação ao negro brasileiro. Como coloca um entrevistado de Massart, que diz: "Aqui no Brasil, a discriminação [racial] é grande. Talvez não para nós; logo que sabem que és estrangeiro, o relacionamento contigo muda" (MASSART, 2002. p. 281).

Essa categorização tem efeitos sensíveis para os estudantes que aqui chegam. Como destaca Mungoi (2012), para o caso dos intercambistas na cidade de Porto Alegre, os grupos de "africanos" tendem a estabelecer redes de contato entre eles mesmos. A proximidade linguística é, para muitos, um dos motivos, uma vez em que o francês é uma língua disseminada em diversos países do continente. Outra similaridade entre os diferentes grupos é a condição na qual se inserem: todos são estrangeiros em outro país. Desta forma, os sujeitos se reúnem em torno desta noção de "africanidade" para se reconhecer e serem reconhecidos neste novo espaço que ocupam.

\section{A internacionalização no âmbito da UFPR: congoleses via PEC-G ${ }^{10}$}

Uma coisa são as leis e os acordos que regem, num plano amplo, os processos de intercâmbio estudantil e migração educacional, seus escopos de atuação e limites. Outro aspecto é, orientado pelos

${ }^{10}$ Programa estudante convênio de graduação (PEC-G) é um programa regido pelo Ministério da Educação e as embaixadas brasileiras em outros países que tem como função promover o ensino superior brasileiro, disponibilizando vagas para sujeitos provenientes de países com os quais o Brasil mantêm relações culturais e educacionais. Como destaca Rizzi (2012) o programa é regido por uma ótica de cooperação Sul-Sul, para fortalecimento dos países desse hemisfério global. 
parâmetros de funcionamento dos programas e instituições, as ações que os sujeitos tomam em suas trajetórias migratórias no Ensino Superior. A parte que se segue busca compreender melhor algumas das estratégias utilizadas por um grupo de estudantes da República Democrática do Congo (doravante RDC) participantes do PEC-G em sua estada na UFPR.

Se agrupam as contribuições dos participantes em um conjunto de cinco blocos temáticas de análise. Com isso se pretende dar um quadro mais ou menos geral daqueles elementos que, em conjuntam, organizam as experiências desses estudantes estrangeiro no Ensino Superior. Busca-se também empreender um quadro das possibilidades de pesquisa que o tema da migração estudantil pode oferecer. Os blocos de análise são os seguintes: "Motivos de vinda para o Brasil"; "Socialização no Brasil"; "Experiência educacionais"; "Preconceito" e "Perspectiva futuras".

Em relação aos "motivos de vinda para o Brasil”, uma observação preliminar se faz necessária. Todos aqueles estudantes entrevistados já possuíam vontade de fazer sua educação superior fora da RDC, e suas primeiras escolhas eram para países francófonos como a França, Bélgica ou Canadá.

Olha, eu nunca pensei em vir pro Brasil... quando eu era mais
jovem eu pensava em sair do Congo sabe... mas lá os jovens
pensam mais na França... na Europa... nos país que fala
francês [...]daí fiquei sabendo com um amigo meu que tinha
um convênio [...]daí ele falou eu fui la na embaixada do Brasil
ouvi que realmente tinha um convênio entre os dois
governos... Brasil e do Congo... e fiz a inscrição [...]daí
passei...e to aqui.

Esse foi o processo de todos os entrevistados. Por mais que já considerassem sair da RDC para estudar, o Brasil não era sua primeira opção. Como vemos na frase a cima, que cria um paralelo interessante com a obra de Abdelmalek Sayad (1998) "todos têm a França na cabeça”, 
todos os estudantes tinham a Europa me mente. Por motivos como falta de dinheiro para morar na Europa ou a alta concorrência para participar dos programas de intercâmbio nestes países, que são a primeira escolha de muitos na RDC, eles acabaram vindo para o Brasil.

Partindo das observações de Sherry Ortner (2006), para quem a agência de sujeitos em um contexto complexo é plasmada pelas relações de poder, o caso dos fluxos internacionais de estudantes é um local onde se pode visualizar tais dinâmicas. Vê-se como uma geopolítica do conhecimento científico toma forma e estabelece os lugares de cada sujeito e suas respectivas trajetórias acadêmicas. Quer dizer, mesmo que estes sujeitos possam fazer planos para um estudo internacional, estes planos estão restritos àquelas possibilidades objetivas e, mais do que isso, conhecidas de cada um sobre a mobilidade estudantil.

A vinda para o Brasil parece orientada por ao menos dois elementos. O primeiro ligado ao custo de vida no país, relativamente menor do que aquele em países europeus, e o segundo pela possibilidade de uma bolsa de estudos. É ainda de se considerar que os atuais fluxos migratórios educacionais se expandam num futuro próximo se os programas continuarem a existir, uma vez que as gerações atuais também disseminam suas experiências para as futuras e como que pavimentam o caminho para as próximas.

A assinatura de acordos estudantis com países do continente africano é uma importante ferramenta para se estabelecer um diálogo e uma colaboração entre países Sul-Sul. Através destes acordos os vínculos intelectuais, econômicos e mesmo afetivos entre os seus cidadãos vão tomando forma. Este fluxo alternativo no movimento internacional de estudantes do continente africano, que agora não estão mais fadados a buscar um estudo internacional na Europa, cria uma nova configuração no campo educacional. A posição do Brasil enquanto agente geopolítico 
parceiro de países como a RDC possibilita o estabelecimento de relações mais duráveis entre os dois países.

No trecho sobre a "socialização no Brasil", nos detemos naqueles aspectos das entrevistas que destacam alguns dos meios encontrados pelos estudantes para estabelecer contato com a sociedade brasileira e para constituir seus próprios espaço dentro dela. É importante notar que é esta socialização que irá, em última análise, levar à cabo os propósitos do projeto de internacionalização do ensino.

É necessário primeiramente dividir os contextos de socialização em dois. De um lado aqueles encontros que tem lugar no ambiente universitário e aqueles que ocorrem fora dele. Quando questionado sobre a sua adaptação ao Brasil, um dos colaboradores diz o seguinte:

\footnotetext{
Cara até que a adaptação não foi complicada... até por ser a universidade as pessoas têm a mente mais aberta assim... pessoas tem uma maneira de pensar diferente tipo [...] consegui fazer amigos já no primeiro ano da faculdade... amizades que eu levo até hoje [...] só que fora da universidade é outro mundo né... a gente teve que se acomodar... entender como as pessoas pensam e tal... foi uma... toda uma aprendizagem.
}

Nota-se aqui aquilo que Subuhana (2009) diz para o caso dos estudantes negros no Brasil. Para ele, a universidade se abre como meio de socialização primeiro. A universidade e seus alunos são entendidos por termos como "ter a mente mais aberta" ou "ter uma maneira diferente de pensar". Aqui se coloca uma questão para a sociologia da (i)migração. Se estes estudantes se integram de alguma maneira durante o período estipulado para os seus estudos, eles se integram, sobretudo, no seio da universidade brasileira, enquanto estudantes universitários, e suas trajetórias são marcadas mais pelas interações no interior da universidade, uma instituição com várias ramificações, do que no seu 
exterior, rumo a sociedade de uma forma mais ampla, representada, sobretudo, pelo trabalho.

Mas qual outro espaço de socialização estes estudantes frequentam fora da universidade? A igreja foi comentada mais de uma vez pelos colaboradores. Alguns deles já havia frequentado igrejas em Curitiba e dois continuam a ir até a Primeira Igreja Batista toda semana. A igreja surge então como um dos poucos lugares fora da universidade no qual estes estudantes estabeleceram relações com brasileiros. ${ }^{11}$

As "experiências educacionais" desses estudantes são marcadas por uma surpresa que tem relação com a já dita preferência pelos estudos no continente europeu. O objetivo é o de compreende como esses estudantes percebem a educação que recebem no Brasil. Algo interessante desse ponto é que todos os entrevistados já haviam, senão terminado, ao menos iniciado seus estudos superiores na RDC. Essa dupla inscrição lhes dá uma capacidade de comparação única entre o sistema de ensino dos dois países.

Chegando ao Brasil e descobrindo mais sobre a realidade brasileira, os estudantes dizem gostar do ensino que recebem na universidade. Um dos pontos destacados é que, diferentemente da RDC, onde as aulas são preenchidas por grande número de alunos, "com 200 pessoas no mesmo momento”, no Brasil as turmas são menores. Uma das vantagens reconhecidas neste modelo é que a relação aluno/professor se torna mais próxima, já que é possível para o professor perceber, dados alguns limites óbvios, as necessidades particulares de cada aluno. Como destacado por um deles:

Eu consigo comparar muito... porque no Congo o sistema pedagógico já permite que tenha muitos alunos numa sala de aula... tipo turmas grandes assim... e além de ter turmas

\footnotetext{
${ }^{11}$ Note-se que os dois colaboradores que comentaram de suas amizades fora da universidade vão na mesma igreja. Novamente isso indica algo importante sobre os meios de socialização dos estudantes estrangeiros no Brasil.
} 
grandes os professores não se [...] preocupam em saber se todo mundo entendeu... afinal são duzentos alunos para um professor... afinal ele é só uma pessoa [...]

Para alguns estudantes, alocados em áreas de saber específicas, o ensino superior brasileiro é referência em sua área. Este é o caso para um estudante de agronomia. Para ele, como as condições climáticas entre o Brasil e a RDC são similares, e uma vez que a pesquisa nesta área é mais forte aqui do que em seu país, vale a pena fazer a graduação no Brasil “dependendo do curso que ele (o estudante) quer fazer... as vezes não compensa né... a agronomia compensa... alguns cursos também... mas tem que estudar bem o curso que quer fazer".

Quando questionados sobre a qualidade do ensino no Brasil e sobre a escolha de ter vindo para cá todos apontam aspectos positivos.

Assim eu não me arrependo de ter vindo para o Brasil para
estudar... pelo menos pra estudar eu não... eu acho tipo assim
não me arrependo porque foi uma oportunidade boa...
porque foi uma coisa assim [...] mais simples assim de
aprender outra língua [...] eu acho assim o Brasil no ponto
assim se for falar do ensino superior apenas... o Brasil ainda
consegue manter uma boa organização no ensino superior...
se for comparar com o Congo né... o ensino superior no
Congo a ementa é boa... tipo o conteúdo é bom... mas a
administração e pedagogia os métodos são um pouco sei lá
rígidos e fechados que não facilita muito a aprendizagem [...]

A essa boa percepção do ensino no Brasil se alia o fato de todos eles dizerem que indicariam o Brasil para possíveis conhecidos na RDC, dadas algumas ressalvas. Além da exposta acima, sobre a escolha da área de estudos, outra é feita sobre a necessária vinculação ao PEC-G. O que eles ressaltam é a importância de entrar no país com duas seguranças. A primeira de que a universidade será gratuita, e a segunda de que terão uma estrutura de apoio, como restaurantes universitários e bolsas de estudos. 
De toda a bibliografia levantada, o tema com maior recorrência é aquele do preconceito ligado ao ser negro no Brasil. Muitos ainda vêm ao Brasil com a ideia de que encontrariam aqui o "paraíso racial", o que, em todo caso, não ocorre. Pelo fato de se encontrarem inseridos na categoria de estudantes universitários e conviverem a maior parte do tempo na universidade, lugar que, como visto anteriormente, é considerado menos discriminatório, a realidades destes sujeitos seja outra.

Nenhum deles relata ter passado por algum caso de ofensa direta por conta de sua cor. O preconceito que aparece com maior frequência é em relação ao continente africano. Segundo eles, muitos ainda partilham do ponto de vista de que na África são todos muito pobres, e que os países são assolados pela fome e pela guerra. Há também o engano corrente de que a África seja não um continente, mas um país. Este equivoco foi comentado mais de uma vez, e um amigo chegou mesmo a comentar que ao fazer o cadastramento no portal do aluno na universidade a África surgia como opção para o campo “país”. É pouco provável que a Europa tenha aparecido como opção para país. Esse desconhecimento, materializado na invisibilidade da diversidade cultural de um continente de grandes proporções como a África, é também decorrência das desigualdades de representação de diferentes espaços. São estas desigualdades que parecem afetar os modos como estes estudantes se inserem na sociedade brasileira, em especial quando precisam se definir, para fins de reconhecimento, como africanos.

Afora as metáforas de pobreza, as metáforas de excessiva riqueza também ocorrem. Com isso quero dizer que os estudantes já foram vistos como sendo muito ricos em seus países de origem, do contrário está é a afirmação que lhes é imposta por seus interlocutores - como seria possível para eles terem saído da África e vindo morar no Brasil? 
Um estudantes se refere a uma experiência tida na Casa do Estudante Universitário do Paraná $^{12}$ da seguinte maneira:

[...] eu esperava que assim por exemplo... pudessem ajudar mais os pobres só que a casa do estudante sempre acha que o estudante africano é rico... que ele é intercambista igual todo... não que a gente seja sei lá pobre... pobre... pobre... mas assim a gente nem é rico quanto eles imaginam né... as vezes eles confundem a gente com os intercambistas que ganham bolsas em euros por exemplo que podem pagar um apartamento de boa porque no final recebem uns três mil reais de bolsa $[\ldots]$

Se tem algum lugar onde o preconceito parece atingir estes estudantes de forma mais impactante é quando estes procuram vagas no mercado de trabalho. Isso é um fator sensível para eles, pois muitos precisam, como condição sine qua non para terminar seus cursos, fazer um estágio obrigatório. Aqueles que não conseguem fazer tal estágio em empresas - o meio de maior destaque para se estagiar em suas áreas completam essas horas em projetos de extensão. Tal dinâmica acarreta em uma volta destes estudantes para a socialização que ocorre dentro da universidade. Desta forma a divisão, muito nítida durante todo o trabalho de pesquisa, entre a vida na universidade e fora dela, se acentua ainda mais para os estudantes estrangeiros e do continente africano.

Para eles o problema do preconceito na hora de entrar no mercado de trabalho também se dá através da díade negro/estrangeiro. Relatam a atual crise econômica brasileira como um dos fatores que piora ainda mais suas situações. Segundo eles, quando o empregador vai disponibilizar uma vaga de trabalho, ele irá dar prioridade para os nacionais. Sobre os dois pontos levantados acima, notadamente, sobre o estatuto de estrangeiro e de estrangeiro negro no Brasil, um dos estudantes comenta sobre a expectativa de entrada no mercado:

${ }^{12}$ Foi nesta instituição de moradia estudantil onde conheci todos os colaboradores do trabalho aqui apresentado. 
por que além de a expectativa ser negativa é pior ainda quando você pensa que você é estrangeiro mas... particularmente africano... no sul do Brasil... e você é negro entende... daí tem tipo um monte de preconceito que influencia qualquer mercado que seja... mesmo a vida acadêmica... mas assim na vida profissional pior ainda sabe.

Cabe falar então sobre as "perspectivas futuras" desses estudantes. Esse trecho é interessante pois nos mostra como, dentro de um contexto de poder, estes sujeitos conseguem se utilizar de certas estruturas para realizar seus planos. Este gradiente de ação pode ser melhor vislumbrado nestas projeções futuras, uma vez em que a possibilidade de mobilidade através de um programa de intercâmbio surge como um impulsionador para planos de vida futuros. Temos então uma questão de escolha com vista a algum fim específico. Quais são os fins buscados pelos estudantes?

Por mais que seja um dos objetivos específicos do programa PEC-G que seus conveniados voltem a seus países com conhecimentos para impulsionar o desenvolvimento do mesmo, poucos tem tal interesse. Somente um estudante de agronomia relatou a sua vontade de voltar para seu país. Para os outros esta seria a última opção. Um deles chega a comentar que não pretende voltar ao seus país pois "não me sinto na obrigação de voltar porque eu sinto que o meu país não contribuiu diretamente assim na minha formação”.

Não consideram também se manter no Brasil. Citam os baixos salários e as poucas oportunidades encontradas no mercado de trabalho como motivos. Aliado está o fato de receberem em reais, pois mesmo na RDC receberiam, na maioria dos casos, em dólares. O preconceito citado anteriormente e a chamada crise econômica pela qual o país passa também são levantados pelos estudantes. Suas trajetórias estão orientadas sobretudo pelo desejo de continuar suas trajetórias migratórias. 
Aqui surge o problema da intenção destes sujeitos. O que as entrevistas nos indicam é que há uma espécie de ação instrumental das oportunidades de mobilidade acadêmica internacional. A inserção destes estudantes em um programa de mobilidade acadêmica foi crucial para a ignição dos projetos internacionais dos participantes. A própria escolha do Brasil como destino aparece, numa das entrevistas como decisão inserida num projeto maior de vida:

[...] se Deus é a vontade dele continuar fazendo uma especialização em outro país americano... do continente americano... por exemplo os EUA e o Canadá... daí quando eu perguntei algumas pessoas me falaram (que) seria melhor você ir (para o) Brasil porque é no mesmo continente que os EUA (e o) Canadá... daí você pode ir continuar ao invés de evoluir na Europa (que) vai ser difícil sair desse continente para outro.

Esta talvez seja a fala onde fica mais nítido que a vinda para o Brasil já se encontrava orientada para iniciar um processo migratório mais amplo, neste caso para a América do Norte. O Brasil surge neste trecho somente como um estágio necessário para se ascender ao local de destino favorito. Novamente, as desigualdades geopolíticas regem a escolha dos locais para onde se deseja ir para estudos e possível moradia. A intencionalidade da escolha do Brasil como destino só faz sentido quando vista dentro de um plano individual maior, qual seja, o de migrar para países e "primeiro mundo".

\section{Dinâmicas migratórios e a internacionalização do ensino superior}

Como então considerar a relação entre a internacionalização do ensino superior e as dinâmicas migratórias consideradas mais tradicionais por serem mais frequentemente estudadas? Três elementos 
surgem como centrais para sintonizar os estudos migratórios com a realidade do ensino superior.

Primeiro, trabalhar com definições de migração mais amplas e menos restritivas. ${ }^{13}$ As definições que não especificam o tipo de sujeito da migração, mas sim os trajetos em que elas ocorrem podem nos ajudar a reconhecer a realidade pela qual muitos estudantes passam, a qual se aproxima, com suas especificidades, da de outros tipos de migrantes, como aqueles a refúgio e a trabalho. Tal ampliação da definição pode também gerar novos problemas para uma agenda de pesquisa na sociologia da migração.

Uma segunda observação importante, e que já foi trabalhada aqui, é a de perceber os potenciais que os fluxos estudantis têm na criação de uma trajetória migratória. Como exposto para o caso dos estudantes da RDC que vieram para o Brasil via PEC-G, percebemos que a agência é orientada por uma ação instrumental com o fim de continuar sua trajetória migratória. A vinda para o Brasil não é um fim em si mesma. Ela precisa ser colocada em perspectiva com uma intenção maior, qual seja, a de migrar para outros países. Somente assim tal empreitada educacional pode ser satisfatoriamente compreendida.

Essa observação feita no âmbito dos fluxos educacionais daqueles que participam do processo de internacionalização do Ensino Superior, pode ser ampliada para outros problemas de pesquisa dentro da Sociologia da Migração. Essa observação põe em questão um termo comumente utilizado na área, aquele de “integração”. Como observa Brito (2010) em relação as migrações para a França, a noção de “integração” não pode mais ser usada com os fins de impor aos sujeitos migratórios um certo "bem-estar" ou a sua "plena socialização”. Não se

${ }^{13}$ Um exemplo é aquele dada por TURNER (2006), no Cambridge dictionary of sociology, que define migração como: "A change in permanent residence, often of a year or more in duration, migration invoves a geographical move that crosses a political boundary". 
trata mais, nesta perspectiva, de uma socialização que se opera de cima para baixo. Não se opera mais a partir da ideia de que aqueles que chegam devem assimilar a cultura do país que os recebe em detrimento de sua cultura “original”.

Por fim, é preciso levar em consideração iniciativas pioneiras no âmbito universitário que tem alterado as portas de entrada e as dinâmicas de internacionalização do ensino superior. Na UFPR, por exemplo, existe um programa chamado PROVAR, ${ }^{14}$ que a partir do ano de 2014 começou a disponibilizar vagas de reinserção na universidade para refugiados e solicitantes de refúgio. Entre 2014 e 2018 foram atendidos 225 processos de reinserção no ensino superior na UFPR. Destes, um total de 48 foram aceitos e estão cursando seus cursos de desejo. Uma taxa de aprovação de $21 \%$. Destas 48 vagas, 35 foram preenchidas por haitianos. $\mathrm{O}$ restante está distribuído entre 2 guineenses; 3 congoleses (RDC); 7 sírios e uma venezuelana, que entrou somente no ano passado, por conta da crise vivida pela Venezuela.

O que tal programa leva a cabo é uma interligação maior entre os fluxos migratórios contemporâneos e a composição internacional da universidade. Para o ano de 2018, vemos que o número de venezuelanos solicitantes de reinserção aumentou, fato que esta em sintonia com fluxos migratórios mais amplos dos mesmos. A Venezuela tem produzido uma grande quantidade de solicitantes de refúgio em toda a região. É importante ressaltar essas proximidades entre os fluxos migratórios de refúgio e aqueles ligados a educação. Somente assim se pode ter uma noção mais completa daquilo que significa estudar os fluxos migratórios contemporâneos.

\footnotetext{
${ }^{14}$ Programa de ocupação de vagas remanescentes
} 


\section{REFERÊNCIAS}

AZEVEDO, Leonardo Francisco. Intercâmbio estudantis: dinâmicas migratórias contemporâneas e o (re) pensar antropológico. Novos debates- fórum de debates em antropologia. v.2, , p.52-59, 2015.

BAUMGARTEN, Maíra. Geopolítica do conhecimento e da informação: semiperiferia e estratégias de desenvolvimento. Liinc em Revista. v. 3, n. 1, p.17-33 mar., 2007.

BRITO, Angela Xavier de. Habitus migrante: um conceito que visa captar o cotidiano dos atores em mobilidade espacial. Revista sociedade $\mathbf{e}$ Estado. v 25, n. 3, p.431-464, set./dez., 2010

Habitus de herdeiro, Habitus escolar: os sentidos da internacionalização nas trajetórias dos estudantes brasileiros no exterior. In. ALMEIDA, A. M.(Org.). Circulação internacional e formação intelectual das elites brasileiras. Campinas: Editora da UNICAMP. 2004.

BRUM, Ceres Karam. Maison du Brésil: um território brasileiro em Paris. In. XXVII Congresso de la asociación latinoamericana de sociología; VIII Jornadas de sociologia de la Universidad de Buenos Aires. Asociación latinoamericana de sociologia,Buenos Aires. 2009.

. Cité universitaire e Maison du Brésil: elite e desterritorialização de identidade de pesquisadores brasileiros em Paris. Antares, v. 5, n. 9, p.83-110, jan./jun., 2010.

. Maison du Brésil: a student residence for the brazilian elite in Paris. Sociology study, v. 1, n. 1, p. 31-48, jun., 2011.

Maison du Brésil: cotidiano, memórias e identidade de um território brasileiro em Paris. Iluminuras, Porto Alegre. v. 16, n. 36, p. 333-359, ago./dez., 2014.

DE WIT, Hans. Changing rationales for the internationalization of higher education. In: Internationalization of Higher Eduation: an institutional perspective. Bucharest:UNESCO. 2000.

FERREIRA, Marieta de Moraes; MOREIRA, Regina da Luz. CAPES: 50 anos: depoimentos ao CPDOC/FGV. Brasília. CAPES. 2002. 
GUIMARÃES, Reinaldo. A diáspora: um estudo exploratório sobre o deslocamento espacial de pesquisadores brasileiros na década de 90. Dados Revista de Ciências Sociais. Rio de Janeiro, v. 45, n. 4, p. 705750, 2002.

KALLY, Alain Pascal. Os estudantes africanos no Brasil e o preconceito racial. In:CASTRO, M. (Org.). Migrações Internacionais: contribuições para políticas. Brasília: CNPD. 2001, p. 463-478.

O ser preto africano no "paraíso terrestre" brasileiro: um sociólogo senegalês no Brasil. Lustopie. p.105-121, 2001.

KNIGHT, Jane. Updated definition of internationalization. Boston. Center for Intenational Higher Education. 2015.

LAUS, Sonia Pereira. Alguns desafios postos pelo processo de internacionalização da educação superior no Brasil. Florianópolis: UFSC. 2004.

LAJUS, Fernando. O fluxo internacional de estudantes no Ensino Superior: internacionalização e intercambistas congoleses na UFPR (2011-2017). Monografia (Bacharel em Ciências Sociais). Curitiba. Universidade Federal do Paraná. 2017.

LOMBAS, Maria Luiza de Santana. A circulação internacional de pósgraduandos e pesquisadores: uma prática de internacionalização da produção do conhecimento? XI Congresso Luso Afro Brasileiro de Ciências Sociais. Salvador. 2011.

MASSART, Guy. Viajantes profissionais e estrangeiros cabo-verdianos no Rio de Janeiro: experiências do outro. In: MAGGIE, Y.; REZENDE, C. B. (Org.). Raça como retórica: a construção da diferença. Rio de Janeiro. Civilização Brasileira. 2002.

MOROSINI, Marília Costa. Internacionalização na produção do conhecimento em IES brasileiras: cooperação internacional tradicional e cooperação internacional horizontal. Educação em Revista. Belo Horizonte. v. 27, n.o1, p. 93-112, 2011.

; LAUS, Pereira Sonia. Internationalization of higher education in Brazil. In. Higher education in Latin America: the international dimension. Washington DC. The World Bank.2005. 
MUNGOI, Dulce Maria Domingos Chale João. Ressignificando Identidades: um estudo antropológico sobre experiências migratórias dos estudantes africanos no Brasil. REMHU: Revista Interdisciplinar da Mobilidade Urbana. Brasília, v. 20, n. 38., p. 125-139, 2012.

NIELSEN, Lauritz Holm B et al. Org. Regional and international challenges to higher education in Latin America. In. Higher education in Latin America: the international dimension. Washington D.C. The World Bank. 2005.

ORTNER, Sherry. Power and projects: reflections on agency In. Anthropology and social theory: culture power and the acting subject. Duke university press. 2006.

PIRES, Rafaela de Oliveira; BERNER, Vanessa Oliveira Batista e FRANÇA, Julia Monteath de. Os estudantes africanos no Brasil na perspectiva da teoria crítica dos direitos humanos. Quaestio Iuris. Rio de Janeiro, v. 09. N. 02, p. 757-787, 2016.

SAYAD, Abdelmalek. A imigração ou os paradoxos da alteridade 1998. Trad. Cristina Murachco. São Paulo. EDUSP.1998.

SCHWARTZMAN, Simon. Um espaço para a ciência: a formação da comunidade científica no Brasil. Brasília. Ministério da ciência e tecnologia. 2001.

SOBRINHO, José Dias. Educação superior, globalização e democratização. Qual universidade. Revista brasileira de educação. $n$. 28, , p.164-173, jan/abr, 2005.

SUBUHANA, Carlos. A experiência sociocultural de universitários da África lusófona no Brasil: entremeando histórias. Pro-posições. Campinas. v. 20, n. 1., p.103-126, jan./abr., 2009.

TURNER, Bryan S. The Cambridge Dictionary os Sociology. Cambridge. Cambridge University Press. 2006.

UNESCO. World Education Report 1998. Paris. UNESCO. 1998. . World Conference in Higher Education 2oog: final report. Paris. UNESCO. 2009. 